University of North Florida

UNIVERSITY of

NORTH FLORIDA.

UNF Digital Commons

Exceptional, Deaf, and Interpreter Education

Faculty Publications

Department of Exceptional, Deaf, and

Interpreter Education

3-2001

\title{
Integration of Computers and Related Technologies into Deaf Education Teacher Preparation Programs
}

Len Roberson

University of North Florida, len.roberson@unf.edu

Follow this and additional works at: https://digitalcommons.unf.edu/eexc_facpub

Part of the Communication Sciences and Disorders Commons, and the Special Education and Teaching Commons

\section{Recommended Citation}

Roberson, Len, "Integration of Computers and Related Technologies into Deaf Education Teacher Preparation Programs" (2001). Exceptional, Deaf, and Interpreter Education Faculty Publications. 2. https://digitalcommons.unf.edu/eexc_facpub/2

This Article is brought to you for free and open access by the Department of Exceptional, Deaf, and Interpreter Education at UNF Digital Commons. It has been accepted for inclusion in Exceptional, Deaf, and Interpreter Education Faculty Publications by an authorized administrator of UNF Digital Commons. For more information, please contact Digital Projects.

(C) 3-2001 All Rights Reserved

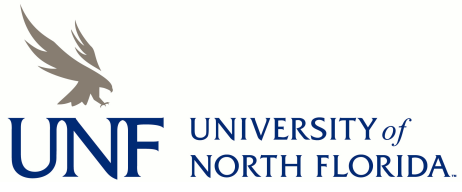


Integration of and Instruction With Computers and Related Technologies in Deaf Education Teacher Preparation Programs

\author{
Len Roberson, $\mathrm{PhD}$ \\ University of North Florida
}

Author's Note:

This is a post-review but pre-publication, final version of this manuscript. The article will be published in the American Annals of the Deaf.

Roberson, L. (2001). Integration of computers and related technologies in deaf education teacher preparation programs. American Annals of the Deaf, 146(1), 60-66.

Correspondence should be directed to Len Roberson, University of North Florida, 1 UNF Drive, Jacksonville, Florida 32224. E-mail: len.roberson@unf.edu. 
Integration of and Instruction With Computers and Related Technologies in Deaf Education Teacher Preparation Programs

\section{INTRODUCTION}

Computers and related technologies have become an integral part of daily life, changing the world in both business and educational systems. A person can go into a supermarket and use an informational kiosk to find recipes and nutritional information about the food they will buy; potential buyers of new vehicles can use a computer to shop for models that best fit their needs; children can travel the world with a few clicks of a mouse and visit far away museums and distant countries; travelers can use an on-line service to make travel arrangements; electronic mail services can be used to correspond with family and friends around the globe; and parents can use a computer to remain upto-date with their child's academic progress. As computers become more and more commonplace in society, children will need not only to learn about computers, but to learn with computers. Teachers must be able to make use of computers and related technologies to get the most out of their tasks and time while providing the best possible educational environment for their pupils. The common, everyday tasks and projects that are part of a teacher's job can become burdensome. The use of computerized technology can minimize such burdens, increase productivity of teachers, and greatly enhance their instructional delivery.

Many teachers are simply not interested in technology and do not have an understanding of the potential impact that technology can have on education and learning. As students enter schools, they bring with them knowledge and experience 
about the use of computers. Teachers need to understand and be able to use computers as well as they understand and use a pencil, a textbook, a ruler, or other type of teaching aid. A review of research conducted in the 1980s (Ryan, 1991) as well as research studies in the 1990s (Handler, 1993; Hickey, 1993) support the assertion that training of teachers in the use of computers and related technologies is essential to effective integration of technology into education.

Teachers in the classroom often model what they have seen in their own preparation to become teachers (Ball, 1990). Therefore, it is crucial to examine current teacher preparation practices to determine how technology is used and taught. Those who are preparing to become teachers would benefit from seeing and using technology during their own coursework and practica in order to learn how to incorporate computerrelated technology into their own classrooms. According to Barron and Goldman (1994), this need of teachers to change how they teach is difficult because the "framework for interpreting what goes on in a classroom is heavily influenced by their own school experience." For new teachers, the most recent "school experience" is the college or university education classes taken in their own professional preparation. Teacher educators in many cases are not modeling how to use technology in the instructional process nor do they require teacher education students to incorporate technology into projects and assignments.

Education is in part a process of communicating thoughts and ideas between and among one person or group of people (the learner) and another person or group (the teacher). This communication process has traditionally depended upon the use of speech and hearing to share the information and knowledge (Roblyer et al., 1997). It is not 
speech and hearing that are essential for communication to and with individuals who are deaf, but rather the sense of vision. Within the deaf community, "vision and its associated activities, such as visual/manual language and attentiveness to the visual environment, are highly valued" (Lane, Hoffmeister, \& Bahan, 1996, p. 408). This value of and attentiveness to the visual environment supports the need for the visual presentation of information.

In the field of deaf education, visual presentation of information is key to successful communication and instruction. When only the spoken word is used in communication and instruction, individuals who are deaf or hard of hearing are not able to participate fully in the learning process. According to I. King Jordan, President of Gallaudet University, "visual access to information for people who rely on vision rather than audition must be regarded as a basic right" (1993, p. 28).

Educational technology offers learners and teachers a method of presenting information both visually and interactively, regardless of communication method, enabling the communication of ideas and thoughts with all students. Educational technology, by offering new visual methods of presenting information to students (e.g., presentation software, the use of the internet, display of video segments) and new modes of communicating with others (e.g., electronic mail, real-time chat), allows the student who is deaf or hard of hearing to be freed from "the limited and sheltered interpretation of the world that heretofore had restricted his learning and his participation" (Propp, 1978, p. 647) because of the emphasis on the audible communication of information. In view of these points, it is pertinent to investigate the readiness of teachers to utilize computer-related technology in their instruction of students who are deaf or hard 
of hearing. There has been limited research conducted to investigate the use or integration of technology in deaf education teacher preparation programs. In a survey of teacher preparation programs in deaf education, Israelite and Hammermeister (1986) found that less than 20 percent of the teacher preparation programs included instruction in computer literacy and application. Rose and Waldron conducted a survey (1984) in which 342 programs serving students who are deaf or hard of hearing within the United States were asked whether or not teachers had received computer training in teacher preparation programs. Less than one percent of the school programs reported that the teachers received such training in technology during their preparation. No studies of teacher preparation programs' use of educational technology have been done in more than ten years. Additional research is needed to update the data on the use and integration of technology in deaf education teacher preparation programs.

\section{Statement of the Problem}

Teacher educators must learn how they, as leaders and role models, can benefit from computers and then begin to put into practice what they learn. There is currently a lack of current data on how technology is integrated into deaf education teacher preparation programs. Therefore, the research questions that guided this study address how computer technology is used, modeled, and taught in teacher preparation programs that prepare future teachers of students who are deaf or hard of hearing. The questions included: (a) What types of computer-related technologies are used by faculty in deaf education teacher preparation programs, both for preparation and instruction in the classroom? (b) What types of computer-related technologies are used by students in deaf education teacher preparation programs, both for preparation and learning in the 
classroom? (c) What technology skills or competencies are deemed important, by deaf education teacher preparation faculty? (d) How are the technology skills or competencies taught or presented to the deaf education teacher preparation students? (e) What instructional strategies are used by faculty in deaf education teacher preparation programs to integrate technology into the curriculum? (f) What technology-related competencies do administrators of programs serving deaf and hard of hearing students expect new teachers of students who are deaf or hard of hearing to possess? (g) What do faculty perceive are the barriers to effective integration of technology into deaf education teacher preparation programs? (h) What do administrators of programs serving students who are deaf or hard of hearing perceive as barriers to effective integration of technology into deaf education classrooms?

\section{REVIEW OF LITERATURE}

\section{$\underline{\text { Technology in Education }}$}

Technology is having an impact on today's society. Computers and other related technologies can be found in businesses, homes, and schools performing a variety of tasks and fulfilling many purposes. Technology has enabled us to communicate with friends, business partners, and family, while at the same time allowing instructional material to be sent from one corner of the earth to another. Technology in some form can be found in most of today's schools (Becker, 1991). Technology allows students to gain information faster and in greater quantities. Through technology, students can receive instruction at their own pace and learning level and then manipulate information and generate material via word processing software. Students are also able to share their 
information with students from other areas of their own country as well as share in the learning process of students from other countries.

\section{The Benefits of Educational Technology}

The integration of educational technology has great potential for students, teachers, and for education. Computer-related technologies have the ability to allow learners and teachers to deal with greater amounts of information from a variety of sources. Computers can also be programmed as assistive learning tools that adapt to varying learning styles and abilities, thus meeting the needs of individuals as well as the needs of an entire group. (Roblyer et al., 1997). When used as aids in the instructional process, computers provide feedback to students on their responses and progress and therefore allow students to learn from their errors as well as from their successes. This ability to individualize instruction is a great benefit of using educational technologies in the instructional and learning process. Students are no longer limited to learning as others learn, but are instead able to use computers to enhance their own, individual learning style.

The use of educational technology enables the learner to become central in the educational process, working, and learning at a comfortable pace (Fawson \& Smellie, 1990). Students are empowered to become active learners when using educational technology and are not forced to conform to the learning styles of others. Through integration of computers and other related technologies, teachers allow students to become more responsible for the outcomes of their learning experiences. Educational technologies are opening doors for students to gain access to new ways of learning and 
expanding the traditional classroom to include the home, the community, and even the world.

\section{Computer Literacy for Teachers}

Computer literacy is not a term with one, concise definition. Instead, there are many definitions and views of computer literacy (Anderson, 1983). Daniel Watt, a research associate at MIT who assisted in the development of the computer language LOGO, defined computer literacy as "the skills, knowledge, values, and relationships that allow the teacher to comfortably use the computer as an instructional tool to prepare students to be productive citizens in a computer-oriented society" (Watt, 1980, p. 26). In this definition, technology is seen as a valuable instructional tool used to assist the teacher in developing the student's potential. Many teachers are trained in the use of computers as a teaching aid, but are not literate in the integration and use of computers in the learning/instructional process.

than presented in other computer literacy models.

\section{Educational Technology and Learners Who are Deaf}

The use of technology in the education of students who are deaf or hard of hearing is documented sparingly in the literature.

In the mid and late 1980s, surveys were conducted to determine how computers were used in programs serving students who are deaf or hard of hearing (Deninger, 1985; Harding \& Tidball, 1982; Rose \& Waldron, 1984). The surveys conducted by Deninger , Harding and Tidball, and Rose and Waldron all examined the availability of computers in the schools and showed a steady increase in the percentage of schools that had computers in use for instructional purposes. Harding and Tidball (1982) reported that 
$42 \%$ of the responding schools had computers in use for instructional purposes while Rose and Waldron (1984) showed 52\% and Deninger's research (1985) showed 79\% had computers in use for instructional purposes. In a comparison with data from Quality Education Data, Inc. (QED), of Denver, Colorado, Deninger (1985) found that the growth of computer technology in schools and classes serving students who are deaf or hard of hearing was similar to that of general education programs.

An examination of earlier research (Deninger, 1985; Harding \& Tidball, 1982; Rose \& Waldron, 1984) reveals that there was an increase in the use of computers for instruction in schools serving students who are deaf or hard of hearing. However, about the same time, training in basic computer literacy and computer applications was included in fewer than 20 percent of deaf education teacher preparation programs (Israelite \& Hammermeister, 1986).

Computer experience and use is significantly related to more positive attitudes toward computers (Loyd \& Gressard, 1984). The attitudes of preservice teachers of students who are deaf or hard of hearing towards computers were examined in a study that was published in 1988 (Mertens \& Wang). The results of the study indicated that computer experience was found to be a major factor in computer confidence. The hypothesis presented in the Mertens and Wang study, that computer experience leads to more positive attitudes toward computers, would suggest that exposure to computers and training in the effective use and integration of technology should occur as part of teacher preparation programs.

Between 1994 and 1996, articles appeared in the literature that supported the use of various forms of technology with students, and people, who are deaf and hard of 
hearing. Harkins (1994) reported that technology has changed the world for deaf and hard of hearing people by making communication more visual through the use of fax machines, pagers, electronic mail, and online services, and the mandate for nationwide telephone relay services. Visual telecommunications is, according to Harkins, important to students who are deaf and hard of hearing because "it can empower them to take initiative at earlier ages than has previously been possible" (pp. 195-196). The motivation to read and write, the instruction of fundamental social rules, and the improvement of family relations can all be enhanced by the use of telecommunications and related technologies. Harkins revealed, however, that schools are not yet ready to equip students in the use of such technology because of the lack of access to technology and qualified staff to train the students in the use of the technology. She asserts that "schools need assistance to update curriculum, technology, and staff skills to meet the new challenges of preparing children for lives as deaf and hard of hearing adults" (p. 196).

Formal discussions, presentations, and professional forums held at the National Symposium on Educational Applications of Technology for Deaf Students in 1992 were used to identify nationally recognized priorities for the use of technology with students who are deaf or hard of hearing (Carroll \& Stuckless, 1994). A total of twenty-one priorities were presented and organized into five topics. The priorities could be used to guide the development and improvement of teacher preparation programs, to enhance public school programs serving students who are deaf or hard of hearing, and to increase 
local, state, and federal support for the integration of technology into the education of deaf and hard of hearing students.

Corbett and Micheaux (1996) contacted several schools for the deaf with questions relative to how the schools deal with technology. Questions focused on issues related to planning for technology, networking, curriculum and instruction strategies, financing, and policy on technology. The responses of three schools were shared in the 1996 reference issue of the American Annals of the Deaf, indicating that the schools for the deaf were integrating technology into the curriculum, planning for future uses of technology, and placing a priority on the financing of computers.

These documented stories serve to reinforce the impact technology can have on educating students who are deaf or hard of hearing as well as the need for further developments in integrating technology into teacher preparation programs. From the many success stories shared in the literature, technology can be seen in traditional forms such as computers, printers, television, and more recent innovations such as telecommunications, CD-ROMs, E-mail, online services, and video relay interpreting. 


\section{METHODOLOGY}

Data were collected through two self-reported survey instruments sent to participants from two different groups: (a) deaf education faculty and (b) administrators of programs serving students who are deaf or hard of hearing. In August 1997, 233 surveys were mailed to the faculty group and 100 surveys were mailed to the administrator group.

There were sixty-eight deaf education teacher preparation programs in the United States identified from the 1997 annual reference issue of the American Annals of the Deaf. The teacher preparation programs surveyed represent 32 states and the District of Columbia. These programs included 47 graduate degree programs and 34 undergraduate degree programs in deaf education. Each program was contacted and asked to provide the names of all faculty within their program who taught courses in the deaf education program. There were 233 faculty members identified and subsequently used for the faculty group.

A second group of participants in this study included administrators of school programs serving students who are deaf or hard of hearing. For the purpose of this study, the definition of an administrator of programs serving students who are deaf or hard of hearing is one who was a member of the Conference of Educational Administrators Serving the Deaf (CEASD) during the 1997-1998 membership year.

Two separate survey instruments were used in this study. The instruments were adapted from a survey instrument developed by Harkins, Loeterman, Lam, and Korres (1996) used for a study conducted on the availability and use of instructional technology 
in schools educating deaf and hard of hearing students. The first was composed of six sections and was administered to the deaf education faculty members of the teacher preparation programs found in the United States. The second instrument was divided into three sections and was administered to the administrator group. The surveys were mailed in August 1997. The participants were asked to return the survey to the researcher by December 1, 1997.

Data were collected through two self-reported survey instruments. There were 233 surveys sent to the faculty group and 100 surveys sent to the administrator group. Of the surveys sent, there were 120 surveys returned to the researcher. Seventy surveys $(30 \%)$ were returned from the faculty group (n=233) and 50 surveys $(50 \%)$ from the administrator group $(n=100)$. The faculty group was classified by regions of the United States and represented all of the 32 states and the District of Columbia which have at least one deaf education teacher preparation program. The 70 surveys returned from the faculty group are representative of all four regions and came from $73 \%$ of the states surveyed. Surveys were returned by faculty in more than $80 \%$ of the states surveyed in the Midwest and the West, $100 \%$ of the states surveyed in the Northeast, and $54 \%$ of the states surveyed in the South.

The faculty group was also classified by the size of the deaf education teacher preparation program as defined by the number of faculty members in each program. There were 16 programs that had only one faculty member in the deaf education program, 33 programs that had 2-3 faculty members, 13 programs that had 4-8 faculty members, and 5 programs that had 11-18 faculty members. Surveys returned from programs with one faculty member represent $7 \%$ of the total surveys returned, surveys returned from programs with 
2-3 faculty members represent $37 \%$ of the total surveys returned. Surveys returned from programs with 4-8 faculty members represent $21 \%$ of the surveys returned. Surveys returned from programs with 11-18 faculty members represent $34 \%$ of the surveys returned. The faculty group was also classified by the number of faculty members in each program. Table 3 shows the survey distribution and return by the size of programs as defined by the number of faculty members in each program. It should be noted that in Table 3, the percentages do not total 100 due to rounding. There were 16 programs that had only one faculty member in the deaf education program, 33 programs that had 2-3 faculty members, 13 programs that had $4-8$ faculty members, and 5 programs that had 1118 faculty members. A review of the returns from each size classification of program, indicates that $37 \%$ of the surveys returned were from programs with $2-3$ faculty members and $34 \%$ of the surveys returned were from programs with 11-18 faculty members.

Surveys returned from programs with a single faculty member account for $7 \%$ of the total surveys returned (See Table 3).

Table 3

Survey Distribution and Return by the Faculty Size of Programs

\begin{tabular}{|c|c|c|c|c|c|c|c|}
\hline \multirow[t]{2}{*}{$\begin{array}{l}\text { Number of } \\
\text { Faculty in a } \\
\text { Program }\end{array}$} & \multirow[t]{2}{*}{$\begin{array}{l}\text { Programs that } \\
\text { Received } \\
\text { Surveys }\end{array}$} & \multicolumn{2}{|c|}{$\begin{array}{l}\text { Programs that } \\
\text { Returned } \\
\text { Surveys }\end{array}$} & \multicolumn{2}{|c|}{$\begin{array}{l}\text { Faculty that } \\
\text { Received } \\
\text { Surveys }\end{array}$} & \multicolumn{2}{|l|}{$\begin{array}{l}\text { Faculty that } \\
\text { Returned Surveys }\end{array}$} \\
\hline & & $\mathrm{n}$ & $\%$ & & $\mathrm{n} \quad \%$ & $\mathrm{n}$ & $\%$ \\
\hline $\begin{array}{l}1 \\
\text { (alone) }\end{array}$ & 16 & 5 & 12 & & 167 & 5 & 7 \\
\hline $\begin{array}{l}2-3 \\
\text { (small) }\end{array}$ & 33 & 21 & 52 & 82 & 5 & 26 & 37 \\
\hline $\begin{array}{l}\text { 4-8 } \\
\text { (medium) }\end{array}$ & 13 & 9 & 23 & 70 & 30 & 15 & 21 \\
\hline $11-18$ & 5 & 5 & 13 & 65 & 28 & 24 & 34 \\
\hline
\end{tabular}


(large)
Total
$\begin{array}{lll}67 & 40 \quad 100\end{array}$
233100
$70 \quad 99$

Note: Percentages may not add up to 100 due to rounding.

Surveys were mailed to 100 administrators and 50 surveys were returned. There were 34 of the 50 surveys returned that had identifying information regarding the program's geographical area of the United States. Surveys were returned from all of the four regions of the United States. Additional analysis of the returned surveys from the administrator group is not possible due to the lack of identifying information.

\section{RESULTS OF THE STUDY}

A frequency distribution of all responses showed 69 of the respondents (99\% of the sample) use computers and printers for instruction during class. The distribution also indicated that $84 \%$ of the faculty responding used VCRs for instruction. The third most often used technology was a video camera, with $56 \%$ of the respondents using this technology for instruction during class. Although $99 \%$ of the faculty responding indicated they use computers during class instruction, only fifty-six percent use internet connections for instructional purposes. The use of the internet for instruction as either a demonstration technique or for presentations to students in class would be one strategy for using computers for instruction that goes beyond computer-generated presentations.

Faculty were asked to indicate the importance of each of 20 competencies that were taken from the National Council for Accreditation of Teacher Education (NCATE) standards developed in 1995. The survey instrument provided a Likert scale of 1, not important, to 5, extremely important. On the rating scale included in this study, three 
would be considered important and four would be considered very important. Table 10 showed that 7 of the 20 competencies (35\%) were rated with a mean rating of 4.0 to 4.99 importance level and 12 of the 20 competencies $(60 \%)$ were rated with a mean rating of 3.0 to 3.99 importance level. This indicated that $95 \%$ of the competencies were considered to be, at a minimum, important for teachers to possess.

Table 10

Question 7: Mean Importance Rating of Technology Competencies by Faculty ( $\mathrm{n}=70)$

\begin{tabular}{lr}
\hline Competency & $\underline{\underline{\mathbf{M}}}$ \\
\hline Use of word processor & 4.41 \\
Awareness of adaptive assistive devices & 4.28 \\
Use of telecommunications & 4.19 \\
Use computer-related terminology & 4.10 \\
Use productivity tools & 4.10 \\
Explore, evaluate, and use technology & 4.03 \\
Practice responsible, ethical and legal use of technology & 4.03 \\
Operate a multimedia system & 3.97 \\
Design, deliver, assess activities using computers for diverse student & 3.80 \\
\multicolumn{1}{l}{ populations } & 3.70 \\
Identify technology resources & 3.68 \\
Use of computers to support problem solving & 3.67 \\
Create multimedia presentations & 3.67 \\
Knowledge of equity, ethics, legal issues related to technology & 3.67 \\
Observe distance learning applications of technology & 3.51 \\
Describe current instructional principles related to the use of technology & 3.48 \\
Use imaging devices & 3.45 \\
Describe and implement basic troubleshooting & 3.41 \\
Use of database applications & 3.19 \\
Use of spreadsheet applications & 2.96 \\
Knowledge of the use of computers in business &
\end{tabular}


Grand Means

Note. Scale used was 5=Extremely important, 4=Very Important, $3=$ Important, 2=Somewhat important, 1=Not important.

As noted in Table 12, only six of the 20 competencies are modeled in deaf education courses by half or more of the faculty responding. The use of computer-related terminology was the most often modeled competency, with $70 \%$ of the faculty responding indicating they model the use of such terminology in their courses. Although deaf education courses reportedly examine the development and adaptation of teaching strategies to accommodate students who are deaf or hard of hearing, only $50 \%$ of the faculty responding model the competency that addresses an awareness of assistive devices.

To further examine the question related to the modeling of the technology competencies, the data were examined by program size. A group was created of respondents who modeled at least 15 of the 20 competencies. A crosstabulation was then conducted comparing those who modeled at least 15 of the 20 competencies by the size of their deaf education programs as defined by the number of faculty teaching in the program. This analysis was

Table 12

Question 8: Percentage of Faculty who Model Competency in Deaf Education Course(s) $(\mathrm{n}=70)$

\begin{tabular}{lr}
\hline Competency & $\underline{\mathbf{\%}}$ \\
\hline Use computer-related terminology & 70 \\
Use of word processor & 61 \\
Use productivity tools & 57 \\
Use of telecommunications & 57
\end{tabular}


Operate a multimedia system $\quad 54$

Awareness of adaptive assistive devices $\quad 50$

Practice responsible, ethical and legal use of technology 49

$\begin{array}{ll}\text { Explore, evaluate, and use technology } & 47\end{array}$

Knowledge of equity, ethics, legal issues related to technology 44

Create multimedia presentations $\quad 43$

Design, deliver, assess activities using computers for diverse student populations $\quad 43$

Observe distance learning applications of technology 40

Identify technology resources $\quad 39$

Use imaging devices $\quad 37$

Use of computers to support problem solving 37

Describe current instructional principles related to the use of technology 37

Use of database applications $\quad 36$

Use of spreadsheet applications $\quad 29$

Describe and implement basic troubleshooting $\quad 24$

Knowledge of the use of computers in business 19

conducted to determine whether or not program size was related to the modeling of the technology competencies. The subgroups for program size were: alone $(n=5)$; small programs of 2-3 faculty members $(n=26)$; medium programs of 4-8 faculty members $(n=15)$; and large programs of 11-18 faculty members $(n=24)$. The results of the crosstabulation indicated that $40 \%$ of the respondents who modeled at least 15 of the 20 competencies were from small programs of two to three faculty per program. Results also indicated that $90 \%$ of the respondents from large programs of eleven to eighteen faculty did not model at least 15 of the 20 competencies.

The survey asked participants to rank, with one being the greatest and eleven being the least, potential barriers that would hinder the use and integration of technology into the courses they taught. Eleven potential barriers were provided in the survey with spaces for participants to add additional barriers. Table 14 presents the eleven barriers 
and indicates the percentage of faculty who felt the barrier was the number one barrier to effective integration of technology into their courses.

The lack of time to prepare and develop new teaching strategies that integrate technology was reported by 29 percent of the respondents to be the greatest barrier. The lack of equipment was reported by 24 percent of the respondents to be the greatest barrier. The lack of training in the use and effectiveness of technology and software was reported by 16 percent of the respondents to be the greatest barrier. The degree of fear and/or discomfort in using technology was reported by 13 percent to be the greatest barrier.

Table 14

Question 10: Faculty Primary Barrier to Effective Integration of Technology $(n=45)$

\section{Barrier} Percent

Lack of time to prepare and develop new teaching strategies that integrate technology

Lack of equipment

Lack of training in the use and effectiveness of technology and software

Degree of fear and/or discomfort in using technology

Lack of technical support personnel (e.g., a technology coordinator)

Lack of software, videotapes, and other essential support materials

Lack of appropriate space for equipment

Lack of information/advice as to what equipment and software to use

Lack of total accessibility to some software applications by students

\section{Summary and Discussion of Findings}

Use of Technology

An important finding of this study was that of the 18 technologies listed, only five 
are used for instruction by more than $50 \%$ of the faculty. These include computers, printers, VCRs, the internet, and video cameras. Only three are used by $50 \%$ or more of the students during class and these include computers, printers, and VCRs. The majority of the technologies listed in the study instrument are not used by most of the faculty. Importance of technology competencies

Another finding of this study was the perceived level of importance of the 20 competencies presented to the participants. Although the competencies were rated differently by each group, $95 \%$ of the competencies were rated as either important or very important by the faculty group and $85 \%$ of the competencies were rated as either important or very important by the administrator group. If the majority of the competencies are believed to be important for teachers to possess, then the same competencies should be taught and modeled in teaching methods courses in programs preparing teachers to work in the field of deaf education. Because the respondents from the faculty group indicated that $95 \%$ of the competencies were, at a minimum, important, one would expect the competencies to be integrated into a teacher preparation program. This result supports the need to examine current teaching methods courses to explore the integration of the competencies into preservice teacher preparation.

The one competency the respondents of the faculty group perceived as less than important was having a knowledge of the use of computers in business, with a mean rating of 2.96. It is understandable that faculty members would not see the need to understand how computers are used in business as important for teachers since they will be using technology directly with students or in preparation for their teaching assignments. 
The respondents from the administrator group perceived that three competencies were less than important. These competencies included the ability to describe and implement basic troubleshooting $(\underline{\mathrm{M}}=2.69)$, the ability to use database applications $(\underline{\mathrm{M}}=2.97)$, and the ability to use spreadsheet applications $(\underline{\mathrm{M}}=2.81)$. Administrators may see these competencies as not important because they do not understand how database and spreadsheet applications can be used in the classroom as tools for maintaining student classroom records, keeping an inventory of class materials, recording and calculating grades, or completing math problems. Although administrators may receive some training in the use of computers in administration, they also need to have an understanding of how technologies can be used for instructional and classroom management purposes. In understanding how teachers and students do, or could, use computer-related technologies for teaching and learning, administrators would be better equipped to make decisions as to the type of technology to purchase and the type of skills that teachers need to develop.

Where the technology competencies are taught or modeled

The findings of this study suggest that faculty members believe that most of what the students know and understand about computers and the technology competencies is self-taught. As indicated earlier, only six of the 20 competencies are modeled or demonstrated in deaf education courses by more than $50 \%$ of the faculty. These six competencies include the use of computer-related terminology, the use of a word processor, the use of productivity tools, the use of telecommunications, the ability to operate a multimedia system, and an awareness of assistive devices. Although faculty members indicated that the majority of the competencies are important, the integration 
and modeling of these competencies is minimal with only 6 of the 20 competencies being modeled by $50 \%$ or more of the faculty. If faculty are not modeling the competencies and the use of technology, the students will not see technology as an integral component of education. Richard Overbaugh (1993) asserts that "effective computer use needs to be modeled by content area instructors across the curriculum or students will view computer use as something that occurs in a computer lab and is best left to the 'computer people' " (p. 12-13).

\section{Barriers to effective integration of technology}

The results found in this study relative to the barriers to effective integration of technology into deaf education courses are consistent with those barriers found in the research of general education teacher preparation programs. Studies conducted by Barron and Goldman (1994) and Brooks and Kopp (1990) concluded that factors such as planning, costs, faculty development, lack of time for learning how to use technology, lack of time for planning to use technology, lack of support, and lack of materials all affect the integration of technology in teacher preparation programs. The findings of this study suggest that some of the same factors hinder the integration of technology in deaf education teacher preparation programs. Both groups of participants, college faculty and school administrators, indicated that three of the top four barriers to integration of technology in deaf education programs include the lack of time to prepare and develop new teaching strategies that integrate technology into the curriculum, the lack of training in the use of technology, and the lack of equipment. Although the two groups of respondents, faculty members and administrators, agreed on three of the top four barriers to integration of technology in deaf education programs, how they approach the barriers 
may actually be different. Faculty members reported that the lack of time to prepare and develop new teaching strategies that integrate new technologies into their teaching is the greatest barrier to effective integration of technology. In this instance, the provision of additional preparation time by reducing other responsibilities would be one solution that administrators could offer faculty members and teachers. Administrators, on the other hand, indicated that the top barrier to effective integration of technology into teaching was the lack of equipment. As a response to what they perceive as the top barrier, administrators devote financial resources to the provision of additional equipment while teachers do not have the time to prepare to use new or existing equipment.

Another top barrier to integration of technology in deaf education programs identified by both groups is the lack of training in the use of the technology. Administrators may hire technology technicians or coordinators to handle much of the computer development and training work. Faculty then become dependent upon these individuals for help and do not learn to use the computers on their own. Faculty may be given the equipment and software to use without being provided the release time from teaching to actually learn how to use the technology they have been given. Although workshops and classes are an effective way of learning how to use technology, observations of effective integration allow faculty to see how technology can be used within the teaching environment. Such observations of colleagues not only will build the skills of faculty, but will decrease their degree of fear and discomfort in using the technology. Travel funds are often reserved for the professional development of faculty to support attendance at conferences and seminars. Administrators can assist faculty in 
building their skills and confidence by providing funds for the observation of effective technology integration.

\section{Implications}

The findings of this study have implications for the future use of technology in deaf education teacher preparation programs. Information reported on how technology is used for instruction and how it is taught to students in these programs indicate that the need remains for integration of technology into the teacher preparation programs as well as improved instructional strategies relative to computers and technology. Survey results also indicate that deaf education teacher preparation programs place high importance on the inclusion of new methods of preparing teachers to educate children in the future.

To be role models of the use of technology, deaf education faculty should be modeling all of the competencies they feel are important for teachers to know and be able to use. When technology is integrated into methodology courses students are given firsthand experiences of the use of technology in teaching and are better equipped to integrate the technology in their own classrooms (Puk, 1993). Although many teacher preparation programs rely on educational technology courses to train teachers in the use of technology, such courses do not demonstrate how technology can be integrated into the daily instructional routines. Students can learn the basic skills associated with technology use from a separate course in educational technology, but must see the technology as a valued part of learning in the teaching methods courses. Often the segregated technology course provides brief introductions to various technological components, but does not offer depth or insight into how technology can be used in the classroom. 
Courses would need to be strengthened by including the use of technology as an instructional strategy. As an example, a methodology course in language instruction for students who are deaf or hard of hearing within a deaf education teacher preparation program could be designed to include:

1. The use of computer-generated presentations for all class sessions;

2. Demonstrations of the use of the internet to visit various web sites that provide sample lesson plans for language instruction with students who are deaf or hard of hearing;

3. The use of spreadsheet applications to conduct informal language analysis on written language samples taken from children who are deaf or hard of hearing;

4. Incorporation of various multimedia programs that assist children who are deaf or hard of hearing with the development of language skills;

In addition to faculty and course development, students need to be required to use technology within their courses. To develop teachers of students who are deaf and hard of hearing who integrate technology into their teaching, we must allow for such integration during their preparation. Most deaf education courses require students to prepare lessons and materials to be shared in class or evaluated by the instructor. Faculty can require that the students use various forms of technology throughout each course. 